\title{
Study and cardiovascular follow-up of children and adolescents undergoing oncohematological treatments: Why, how, and when?
}

\section{Estudio y seguimiento cardiovascular de niños y adolescentes sometidos a tratamientos oncohematológicos. ¿Por qué, cómo y cuándo?}

María G. Jiménez-Carbajal*

Pediatric Interventional Cardiology/Pediatric Echocardiography, Centro Médico ABC, Mexico City, Mexico

\begin{abstract}
Review of several international publications in the medical literature related to cardiovascular evaluation in pediatric patients undergoing some type of oncohematological treatment, providing risk factors that together with chemo and/or radiotherapy impair adequate cardiovascular function in a particular way.
\end{abstract}

Key words: Cardiotoxicity. Oncohematological treatments. Children and adolescents.

\section{Resumen}

Estudio de revisión de diversas publicaciones internacionales en la literatura médica relacionados con la evaluación cardiovascular en pacientes en edad pediátrica sometidos a algún tipo de tratamiento oncohematológico, previendo factores de riesgo que en conjunto con la quimioterapia y/o radioterapia merman el adecuado funcionamiento cardiovascular de forma particular.

Palabras clave: Cardiotoxicidad. Tratamientos oncohematológicos. Niños y adolescentes.

\section{Introduction}

Given the significant increase in the diagnosis and treatment of oncohematological diseases in pediatric patients, based on chemotherapy and radiotherapy, and knowing that cardiovascular complications are the second cause of morbidity and mortality in surviving patients, it is necessary to know and disseminate the theoretical foundations of the effects of the therapeutics used for this purpose, as well as the bases for early detection and management of the adverse events that are related to them.

\section{Method}

This is an international review study of published data motivated by the observation of the complications occurring in patients with oncohematological conditions,

\section{Correspondence:}

*María G. Jiménez-Carbajal

E-mail: mgjcmed@yahoo.com.mx/

unicardin@gmail.com
Date of reception: 18-07-2019

Date of acceptance: 04-05-2020

DOI: 10.24875/ACME.M20000157
Available online: 02-03-2021 Arch Cardiol Mex (Eng). 2020;90(4):473-481 www.archivoscardiologia.com 2604-7063 / C 2020 Instituto Nacional de Cardiología Ignacio Chávez. Published by Permanyer. This is an open access article under the CC BY-NC-ND license (http://creativecommons.org/licenses/by-nc-nd/4.0/). 
both during the administration of drugs and in those who are already at survival stage, with the increase in cardiovascular risk inherent to by all known modifiable and non-modifiable population factors.

\section{Results}

\section{Epidemiology}

At present, there is an estimated cure rate higher than $80 \%$ of children with oncohematological conditions, which increases disease-free life expectancy, but increases multiorgan toxicity, including cardiac toxicity, which generates the need for early detection and management of complications to improve patient quality of life ${ }^{1-3}$. Nearly $60 \%$ of pediatric patients with oncohematological diseases receive anthracyclicnes ${ }^{3}$. It has been estimated that up to $65 \%$ of childhood cancer survivors treated with anthracyclines could experience subclinical myocardial dysfunction ${ }^{4}$; in this group of patients, cardiovascular disease is the main cause of cardiotoxicity-associated morbidity and mortality, after cancer recurrence and secondary malignancies ${ }^{1,5-7}$. The incidence of clinical heart failure has been reported to be as high as $16 \%, 0.9-4.8$ years after chemotherapy ${ }^{1,5}$.

\section{Cardiotoxicity}

Cardiotoxicity refers to cardiovascular alterations derived from oncohematological treatments ${ }^{8}$. It can be defined based on the left ventricular ejection fraction (LVEF) deterioration as Grade I: LVEF reduction of 10$20 \%$ with regard to baseline; Grade II: $>20 \%$ reduction or drop below normal; and Grade III: appearance of symptoms of congestive heart failure ${ }^{9,10}$. The American Society of Echocardiography and the European Association of Cardiovascular Imaging use $53 \%$ as LVEF normal limit ${ }^{8,11}$.

\section{Risk factors}

\section{Modifiable}

- Therapy-related factors such as anthracyclines cumulative dose, total doses administered in a day or cycle, and concomitant administration with other cardiotoxic agents. There are reports of the left ventricular (LV) dysfunction at doses as low as $240 \mathrm{mg} / \mathrm{m}^{2}$, which is why some authors consider that there is no "safe dose" of the drug 1,12,13. Mediastinal irradiation with or without anthracycline treatment is another risk factor for cardiotoxicity, which occurs in cases of radiation to the heart even with low doses ${ }^{14-16}$. Cranial irradiation is also a risk factor for cardiovascular diseases and abnormalities, probably mediated by growth hormone deficiency and related to lower LV mass ${ }^{17-19}$

- Individual factors include sedentary lifestyle, electrolyte abnormalities (mainly hypokalemia and hypomagnesemia), hypertension, dyslipidemia, endocrinopathies, obesity, diabetes, drug or alcohol use, and smoking ${ }^{1,12}$.

\section{NON-MODIFIABLE}

Pediatric age tumors can have lower latency periods, grow faster, and become highly invasive; most of them exhibit histological types that resemble fetal tissues at different stages of development and are considered to be of embryonic type, which generates large morphological diversity with varying degrees of cell differentiation ${ }^{12}$. Age $<5$ years at the time of treatment initiation represents an important risk factor for cardiotoxicity with an increase in afterload and a decrease in LV mass and walls thickness ${ }^{1,12,20,21}$. Female patients have a higher percentage of body fat, and doxorubicin is poorly soluble in fat; therefore, the higher risk among girls may be related to lower doxorubicin concentrations $^{22,23}$. Children with preexisting cardiovascular conditions, children with cancer and elevated pretreatment troponin concentrations, some tumor genetic types (HFE C282Y mutation), as well as patients with chromosomal diseases such as trisomy 21 have a higher risk of anthracycline-related cardiotoxicity ${ }^{13,24-26}$.

\section{Classification}

Cardiotoxicity can occur during treatment and up to 40 years after the conclusion of therapy, and it is classified as acute or subacute when it develops from the start of treatment to up to 2 weeks after completion ${ }^{27,28}$, and chronic when toxicity appears after 1 year of therapy completion. The latter, in turn, is divided into early when it occurs within the $1^{\text {st }}$ year after therapy and late if it occurs years after completion ${ }^{10,29-31}$.

\section{Cardiotoxicity mechanism}

The goal of chemotherapy is to inhibit cell division; however, its clinical effect is not selective, it affects non-cancerous cells of the body and generates toxicity ${ }^{27,32}$. Antineoplastic drugs that entail the risk of producing cardiotoxicity are classified into two types ${ }^{27}$ : 
Table 1. Potentially cardiotoxic drugs used in pediatric oncohematology

\begin{tabular}{|c|c|c|}
\hline Drug & Uses in pediatric oncohematology & Cardiovascular effects \\
\hline $\begin{array}{l}\text { Anthracyclines (doxorubicin, daunorubicin, } \\
\text { idarubicin, and/or epirubicin) }\end{array}$ & $\begin{array}{l}\text { ALL, various solid tumors such as } \\
\text { osteosarcoma }\end{array}$ & $\begin{array}{l}\mathrm{DCM}, \mathrm{RCM} \text {, arrhythmias, } \mathrm{OT} \text { interval } \\
\text { prolongation, sinus node dysfunction, } \mathrm{HF}\end{array}$ \\
\hline Bleomycin & $\mathrm{HL}$, germ cell tumors, carcinomas & Ischemia, pericarditis, pulmonary fibrosis \\
\hline $\begin{array}{l}\text { Cyclophosphamide, ifosfamide } \\
\text { (in combination) }\end{array}$ & NHL, leukemia, HL, Burkitt lymphoma & $\begin{array}{l}\text { Acute cardiotoxicity, from subtle } \\
\text { arrhythmias to fatal DCM. Myocarditis, HF }\end{array}$ \\
\hline 5-Fluoruracil & $\begin{array}{l}\text { Hepatoblastoma, rhinopharyngeal } \\
\text { carcinoma, germ cell tumors }\end{array}$ & $\begin{array}{l}\text { Arrhythmias, ischemia, HF, and sudden } \\
\text { death }\end{array}$ \\
\hline $\begin{array}{l}\text { Multikinase inhibitors, sunitinib and } \\
\text { sorafenib }\end{array}$ & CML & $\begin{array}{l}\text { Angor pectoris, HF, electrocardiographic } \\
\text { alterations }\end{array}$ \\
\hline Vincristine, vinblastine & $\begin{array}{l}\text { LLA, lymphoma, Wilms' tumor, Ewing's } \\
\text { sarcoma, neuroblastoma, and } \\
\text { rhabdomyosarcoma }\end{array}$ & $\begin{array}{l}\text { HBP, myocardial ischemia, veno-occlusive } \\
\text { complications }\end{array}$ \\
\hline Cytarabine & Some types of leukemia & $\begin{array}{l}\text { Pericarditis pericardial effusion, cardiac } \\
\text { tamponade }\end{array}$ \\
\hline Cisplatin, carboplatin & Brain tumors, osteosarcoma & $\begin{array}{l}\text { AF, SVT, left bundle branch block, and } \\
\text { myocardial infarction }\end{array}$ \\
\hline Bevacizumab & $\begin{array}{l}\text { Lung, ovarian, fallopian tube, primary } \\
\text { peritoneal cancer }\end{array}$ & HBP, ATE, HF, ischemia, SVT \\
\hline Irinotecan & $\begin{array}{l}\text { Medulloblastoma, primitive } \\
\text { neuroectodermal tumors, } \\
\text { rhabdomyosarcoma, and neuroblastoma }\end{array}$ & Bradycardia, hypotension \\
\hline Steroids & ALL & HBP, OT interval prolongation \\
\hline
\end{tabular}

ALL: acute lymphoblastic leukemia; DCM: dilated cardiomyopathy; RCM: restrictive cardiomyopathy; HF: heart failure; RLL: refractory lymphoblastic leukemia; LV: left ventricle; NHL: non-Hodgkin lymphoma; HL: Hodgkin's lymphoma; CML: chronic myeloid leukemia; HBP: high blood pressure; ATE: arterial thromboembolism; AF: atrial fibrillation; SVT: supraventricular tachycardia.

- Type I: anthracycline-induced cardiotoxicity. Anthracycline cardiac toxicity is dose dependent and causes irreversible cardiac damage ${ }^{27}$. No patient receiving anthracyclines is exempt from cardiac damage, even if it is minimal ${ }^{3}$. Its presentation can be acute (dose independent and transient, related to type 1 hypersensitivity) or chronic (cumulative dose dependent, associated with an increase in apoptosis) $)^{27,33-35}$. Dilated cardiomyopathy might progress to restrictive cardiomyopathy, due to a decrease in the number of functional cardiomyocytes and stem cells able to regenerate cardiac tissue $e^{4,20,36-38}$ - Type II: trastuzumab cardiotoxicity. It causes reversible cardiac harm that allows functionality recovery and restart of the regimen if indicated ${ }^{12,27,39}$

- Combination therapy with type I and II agents is associated with a higher incidence of cardiotoxicity $(27 \%)^{27,33,40}$.

There are other cardiotoxic drugs. Table 1 describes some of the drugs most widely used in pediatric oncology and hematology, referring their cardiovascular effects $4,8,9,12,20,36-38,40$.

\section{Mechanism of radiation damage}

Radiation therapy can cause cardiotoxic side effects such as myocardial fibrosis, cardiomyopathy, early coronary disease, and valve and electrophysiological dysfunction. This cardiotoxicity is dose dependent and is correlated with the exposed area of the heart, the radiological technique, and patient age, with a higher incidence in younger patients. It is caused by acute damage and inflammation. Patients who receive more than 1500-3500 cGy show a 2- to 6-fold increased risk of heart disease, with high doses being related to myocardial ischemia from 12 years after treatment ${ }^{34,41-43}$.

\section{Diagnosis}

All patients who will be treated with potentially cardiotoxic anticancer drugs should have a thorough clinical examination where the presence of a history of cardiovascular conditions such as congenital heart disease, heart valve disease, cardiomyopathy, history of 
LV dysfunction, even asymptomatic, previous treatment with antineoplastic drugs, or previous chest irradiation should be evaluated. Vital signs frequent monitoring is recommended during chemotherapeutic agents infusion ${ }^{9}$.

\section{Electrocardiogram}

It is recommended in all patients before and during treatment. Any electrocardiographic sign of cardiac toxicity such as resting tachycardia, ST interval changes, conduction disorders, QT interval prolongation, or arrhythmias should be detected. These alterations are non-specific, can be transient, and may not be related to the development of chronic cardiomyopathy ${ }^{44}$.

\section{Echocardiogram}

LVEF baseline assessment should be obtained at treatment initiation for comparison with subsequent studies. A LVEF $<53 \%$ is a risk factor for the development of heart failure, if it is $\leq 50 \%$, starting a treatment regimen with drugs with high cardiotoxic potential is not recommended, and the possibility of an alternative regimen should be evaluated together with the oncologist. Although LVEF is the universally used parameter for decision-making, it is not sensitive for subclinical cardiac compromise early detection and depends on the preload and afterload changes that lead to transitory changes in it. Myocardial velocities determination with tissue Doppler at the level of the mitral annulus has been found to possibly be more sensitive for the detection of incipient ventricular dysfunction ${ }^{9,45}$. Pulsed Doppler of the LV inflow tract allows assessing for the presence of a restrictive pattern: an increased E/E' ratio $(>15)$ is a specific parameter of end-diastolic pressure increase and is associated with the development of heart failure ${ }^{9,46}$. Strain and strain rate determination currently play a preponderant role in ventricular dysfunction early detection ${ }^{9,47-49}$. At baseline conditions, global longitudinal strain (GLS) improves cardiotoxicity-related ventricular dysfunction risk stratification versus 2D-LVEF. During antitumor treatment, GLS detects myocardial damage earlier and with less variability than LVEF. The combined use of GLS and troponin I improves the negative predictive value for ventricular dysfunction ${ }^{8}$. At present, the preferred method for estimating LVEF is by three-dimensional echocardiography, which has less variability with regard to the two-dimensional method $^{8}$. It should be performed every time this resource is available.

\section{Magnetic resonance imaging}

It is the method of choice for cardiac mass, volumes, and ejection fraction evaluation. It is mainly used when echocardiography images are suboptimal or when there is discrepancy in LVEF measurement ${ }^{27}$.

\section{Nuclear medicine}

It has high reproducibility in LVEF calculation with low interobserver variability. Disadvantages include exposure to ionizing radiation and impossibility for the valves and pericardium to be evaluated ${ }^{27}$.

\section{Biomarkers}

Specific plasma biomarkers of myocardial injury are a useful tool for cardiotoxicity early detection and evaluation ${ }^{50}$.

\section{Troponins}

Troponins are myocardial injury markers par excellence ${ }^{51}$. Elevated levels of both troponin $T$ and troponin I have been detected in patients receiving various chemotherapeutic agents when early determined with regard to the time, the antineoplastic treatment is received. This is correlated with a higher incidence and severity of LV dysfunction at follow-up ${ }^{52-54}$. In patients who receive trastuzumab and show troponin I elevations, there is a higher possibility for them to develop ventricular dysfunction and to have a lower probability of recovery in comparison with those patients with troponin normal levels ${ }^{55}$.

\section{Natriuretic peptides}

Brain natriuretic peptide (BNP) and the amino-terminal fraction of pro-BNP (NT-pro-BNP) are biomarkers with prognostic value and a possible guidance for the treatment of patients in this context ${ }^{53,56}$. In the setting of the LV dysfunction and heart failure associated with chemotherapy-induced cardiotoxicity, there is sufficient evidence that persistent elevations of these markers are associated with higher risk for developing ventricular dysfunction (both systolic and diastolic) ${ }^{57-59}$.

\section{Endomyocardial biopsy}

It is the most reliable method for assessing myocardial injury; however, given that it is an invasive 
procedure that obtains small myocardial samples and does not provide functional information, its use has been restricted to the monitoring and diagnosis of cardiotoxicity ${ }^{27}$.

\section{Cardiotoxicity prevention}

It is mandatory to promote a heart-healthy lifestyle with regular physical exercise programs for all patients, regardless of the planned treatment ${ }^{8}$. Not exceeding a dose equivalent to $375 \mathrm{mg} / \mathrm{m}^{2}$ of doxorubicin is recommended in children, and this threshold should be reduced to $300 \mathrm{mg} / \mathrm{m}^{2}$ in case of associated radiation to the cardiac area ${ }^{60}$. Anthracycline prolonged infusions $(>6$ and up to $48 \mathrm{~h}$ ) have been proposed instead of boluses; however, some authors propose that prolonged exposure of cardiomyocytes to anthracyclines could cause greater cardiac damage. This approach has the disadvantage that it compromises the possibilities of cure and, in addition, doses below the proposed ceiling dose have been shown to produce subclinical cardiac damage $^{3}$. Administration of anthracycline analogues, such as epirubicin, has also been proposed, although Grades 1 and 2 cardiotoxicity has been observed $^{3,31}$, or liposomal doxorubicin administration, which is associated with free doxorubicin low concentrations, with limited distribution in the myocardium ${ }^{3}$. The use of dexrazoxane, an iron chelating agent that inhibits lipid membranes peroxidation with a decrease in anthracycline secondary cardiotoxicity ${ }^{27}$, should be considered. Limiting the radiation dose to the cardiac area is also essential to reduce long-term sequelae and complications of chest irradiation. At present, the recommended dose in children and adolescents treated for Hodgkin's disease after two cycles of chemotherapy is 20 Gy (vs. 30 Gy in previous protocols) ${ }^{60}$.

\section{Treatment}

The drugs that are commonly studied and used to treat cardiotoxicity are angiotensin-converting enzyme inhibitors (ACEls); however, the beneficial effects of these drugs and their ability to reduce the morbidity and mortality associated with anthracycline in childhood cancer survivors appear to be transitory ${ }^{36}$. Carvedilol provides cardioprotection by inhibiting reactive oxygen species, scavenging free radicals, preventing lipid peroxidation, and increasing Vitamin E concentrations ${ }^{42}$. Acute and chronic heart failure should be treated according to the time of presentation.

\section{Recommendations for cardiovascular evaluation and follow-up}

There is no current international consensus on the follow-up of pediatric patients undergoing oncohematological treatments. Some guidelines developed by expert groups recommend pediatric patients evaluation before chemotherapy by assessing LV systolic and diastolic function (initial permissible LVEF $>50 \%$ ). Another evaluation is recommended after half of the total cumulative dose prescribed in the treatment protocol or on reaching $200 \mathrm{mg} / \mathrm{m}^{2}$ of doxorubicin, then every $100 \mathrm{mg} / \mathrm{m}^{2}$ thereafter. In the case of patients with an initial LVEF $<30 \%$, the risk-benefit ratio with regard to antitumor treatment should be studied, discouraging the use of cardiotoxic drugs, especially anthracyclines. In patients with a baseline LVEF between 30 and $50 \%$, echocardiographic evaluation should be performed before each chemotherapy cycle $^{12}$. Patients receiving higher doses of anthracyclines and those receiving combination therapies should have more frequent systolic function assessment. In patients with echocardiographic evidence of valve disease and with a history of central catheters, evaluation and prophylaxis for bacterial endocarditis should be carried out ${ }^{61}$. Carotid and subclavian artery stenosis (10 years after having received radiation therapy) should be ruled out in patients treated with radiation fields that included these vessels at a dose of $40 \mathrm{~Gy}^{61}$.

In the consensus and recommendations document published in 2017 by López Fernández et al. in Spain, some guidelines are established for initial and longterm follow-up of patients undergoing antitumor therapies during treatment, in cases of decreased LVEF, and in those undergoing radiotherapy ${ }^{8}$ (Figs. 1-3). Although they are not specifically aimed at pediatric patients, they can be considered as a reference in clinical practice, always individually considering patient clinical status for assessments.

\section{Multidisciplinary teams in cardio-onco- hematology}

Cardio-onco-hematology teams bring together the professionals involved in the care of patients with cancer, with the purpose to facilitate treatment and minimize cardiovascular toxicity. The development of protocols for the prevention and early treatment of cardiotoxicity will avoid early discontinuation of antitumor drugs and will allow optimizing health outcomes and reducing costs $^{8}$. 


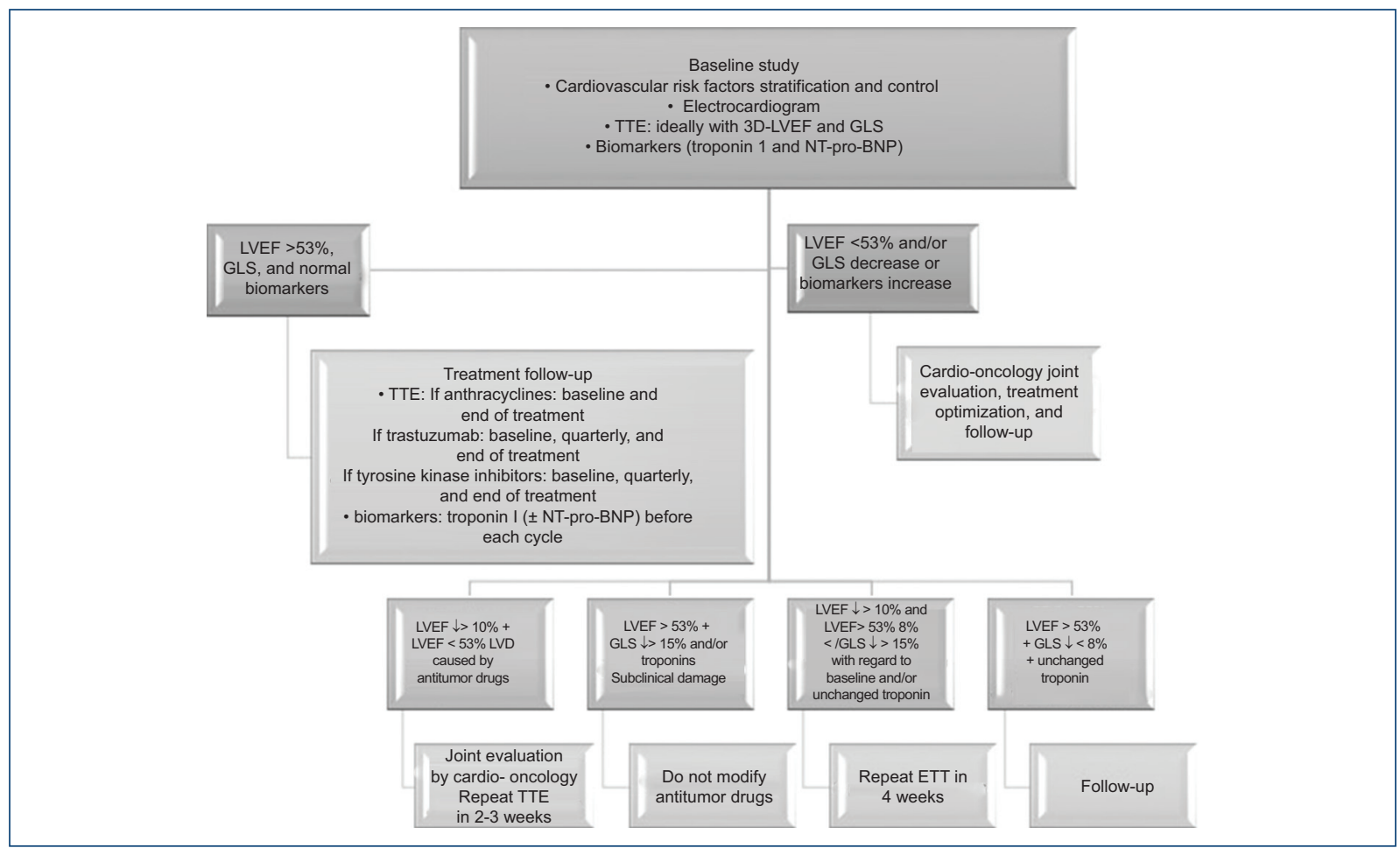

Figure 1. Algorithm for evaluating the treatment of patients receiving antitumor drugs. TTE: transthoracic echocardiogram; LVEF: left ventricular ejection fraction; GLS: global longitudinal strain; NT-pro-BNP: aminoterminal fraction of pro-brain natriuretic peptide; LVD: left ventricular dysfunction.

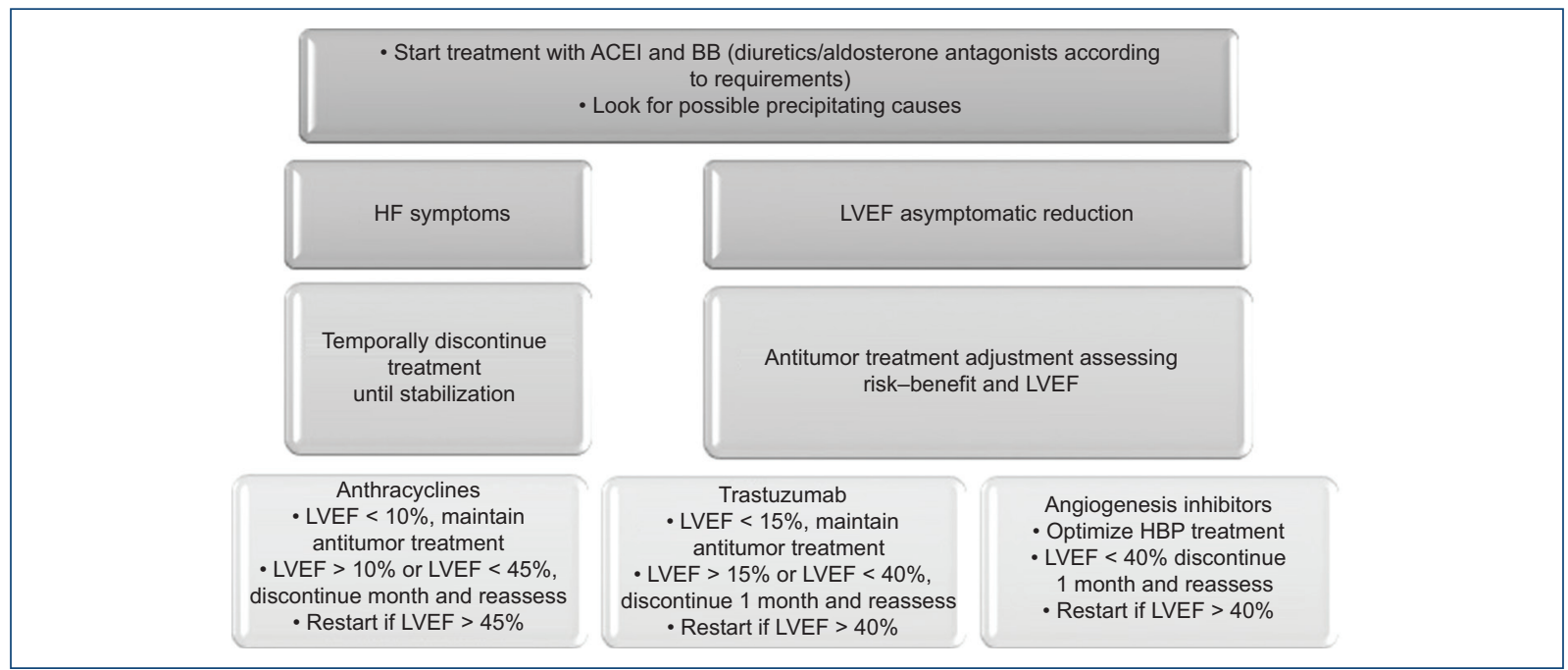

Figure 2. Algorithm for evaluation and treatment of patients with decreased LVEF receiving antitumor drugs. LVEF: left ventricular ejection fraction; BB: beta-blockers; HF: heart failure; HBP: high blood pressure; ACEl: angiotensin-converting enzyme inhibitors.

\section{Discussion}

Cancer early diagnosis and efficacy of its treatment have currently led to a decrease in mortality; however, this has also brought reversible and irreversible cardiovascular complications; in some cases, the risk of death even exceeds the risk associated with tumor relapses ${ }^{62}$, which is why it is important to identify risk factors, as 


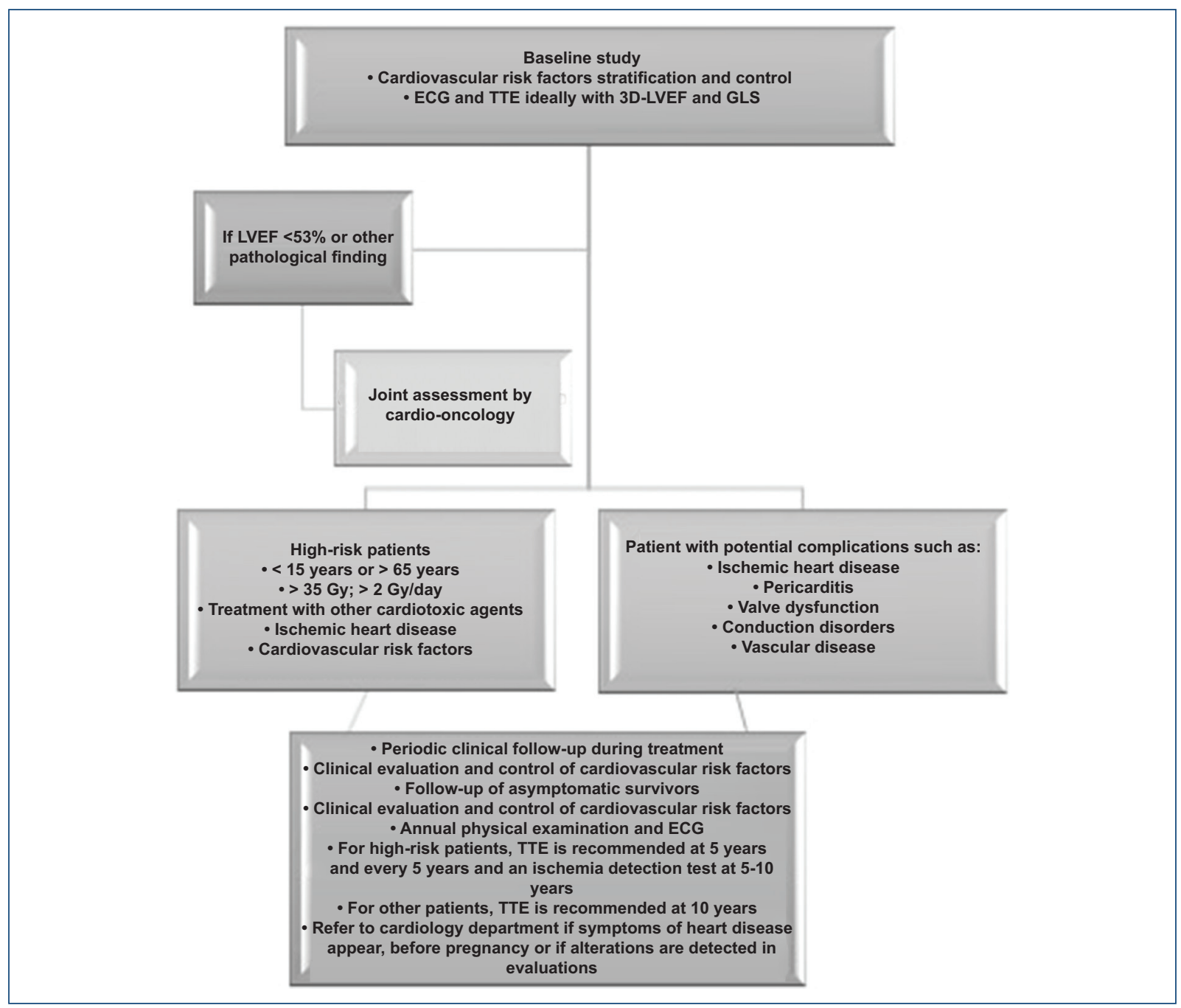

Figure 3. Algorithm for the follow-up of patients undergoing radiotherapy treatment that includes all or part of the heart. TTE: transthoracic echocardiogram; LVEF: left ventricular ejection fraction; GLS: global longitudinal strain

well as close follow-up by the cardiologist, oncologist, or hematologist through the interaction between each one of them, for adequate monitoring of each patient to be carried out. Although there are some recommendations from expert groups for children and several more for adults, it is possible to build on those that best adapt to patient characteristics and those of the multidisciplinary team. Thus, in addition to the aforementioned follow-up strategies, the one published by Plana et al. in 2014 can be cited, where in the case of treatment with anthracyclines, a baseline echocardiographic evaluation is recommended, with a new evaluation at treatment completion and after 6 months. If the used dose is $>240 \mathrm{mg} / \mathrm{m}^{2}$, evaluation is recommended at each additional treatment cycle ${ }^{11}$. It should be remembered that the main strategy to minimize cardiotoxicity is early detection, for ventricular dysfunction preventive treatment to be early implemented ${ }^{50}$.

\section{Conclusions}

There are a significant number of oncohematological diseases in children with various antitumor therapies, which due to their nature affect the cardiovascular system as a whole, and it is, therefore, necessary for pediatric cardiologists, oncologists, and hematologists to be aware of the potential effects of the drugs and risk factors, as well as of cardiotoxicity primary and secondary prevention. The formation of multidisciplinary work teams with the necessary human and material 
resources (cardio-onco-hematology clinics) is recommended, which in the long term will be reflected in hospital costs and in a positive physical and emotional impact on the patient and his/her family, as well as in an improvement in the comprehensive quality of care.

\section{Funding}

This research has not received any specific grant from agencies of the public, commercial, or non-profit sectors.

\section{Conflicts of interest}

The author declares that she has no conflicts of interest.

\section{Ethical disclosures}

Protection of human and animal subjects. The author declares that no experiments have been performed on humans or animals for this research.

Confidentiality of data. The author declares that she has followed the protocols of her work center on the publication of patient data.

Right to privacy and informed consent. The author declares that no patient data appear in this article.

\section{References}

1. Lipshultz SE, Diamond MB, Franco VI, Aggarwal S, Leger K, Santos MV, et al. Managing chemotherapy- related cardiotoxicity in survivors of childhood cancers. Paediatr Drugs. 2014;16(5):373-89.

2. Vargas-Neri JL, Castelán-Martínez OD, de Jesús Estrada-Loza M, Betanzos-Cabrera Y, Rivas-Ruiz R. Anthracycline-induced cardiotoxicity: report of fatal cases. Rev Med Inst Mex Seguro Soc. 2016;54(3):404-8.

3. Gallegos CS. Estrategias de cardioprotección en oncohematología pediátrica. GAMO. 2009;8(3):35-9.

4. Lipshultz SE, Colan SD, Gelber RD, Perez-Atayde AR, Sallan SE, Sanders SP. Late cardiac effects of doxorubicin therapy for acute lymphoblastic leukemia in childhood. N Engl J Med. 1991;324(12):808-15.

5. Kremer LCM, van Dalen EC, Offringa M, Voute PA. Frequency and risk factors of anthracycline-induced clinical heart failure in children: A systematic review. Ann Oncol. 2002;13(4):503-12.

6. Mertens AC, Liu Q, Neglia JP, Wasilewski K, Leisenring W, Armstrong GT, et al. Cause-specific late mortality among 5-year survivors of childhood cancer: The Childhood Cancer Survivor Study. J Natl Cancer Inst. 2008;100(19):1368-79

7. Tukenova M, Guibout C, Oberlin O, Doyon F, Mousannif A, Haddy N, et al. Role of cancer treatment in long-term overall and cardiovascular mortality after childhood cancer. J Clin Oncol. 2010;28(8):1308-15.

8. López-Fernández T, Martín García A, Santaballa Beltrán A Montero Luis Á, García Sanz R, Mazón Ramos P, et al. Cardio-onco-hematología en la práctica clínica. Documento de consenso y recomendaciones. Rev Esp Cardiol. 2017;70(6):474-86.

9. Zylberman M, Agüero R. Consenso de diagnóstico, prevención y tratamiento de la cardiotoxicidad por tratamiento médico del cáncer. Rev Argent Cardiol. 2013;81(5):1-64.

10. Albini A, Pennesi G, Donatelli F, Cammarota R, De Flora S, Noonan DM Cardiotoxicity of anticancer drugs: the need for cardio-oncology and cardio-oncological prevention. J Natl Cancer Inst. 2010;102(1):14-25.

11. Plana JC, Galderisi M, Barac A, Ewer MS, Ky B, Scherrer-Crosbie M et al. Expert consensus for multimodality imaging evaluation of adult patients during and after cancer therapy: a report from the ASE and the EACVI. J Am Soc Echocardiogr. 2014;27(9):911-39.
12. Santos MV, Paiva MG, Macedo CR, Petrilli AS, Azeka E, Jatene IB, et al.; Sociedade Brasileira de Cardiologia. I Diretriz brasileira de cardio-oncologia pediátrica da Sociedade Brasileira de Cardiologia. Arq Bras Cardiol. 2013:100(5 Supl.1):1-68.

13. Trachtenberg BH, Landy DC, Franco VI, Henkel JM, Pearson EJ, Miller TL, et al. Anthracycline-associated cardiotoxicity in survivors of childhood cancer. Pediatr Cardiol. 2011;32(3):342-53.

14. Adams MJ, Lipshultz SE. Pathophysiology of anthracycline and radiation-associated cardiomyopathies: implications for screening and prevention. Pediatr Blood Cancer. 2005;44(7):600-6.

15. Gilladoga AC, Manuel C, Tan CT, Wollner N, Sternberg SS, Murphy ML. The cardiotoxicity of adriamycin and daunomycin in children. Cancer. 1976;37(2 Suppl):1070-8.

16. Little MP, Azizova TV, Bazyka D, Bouffler SD, Cardis E, Chekin S, et al. Systematic review and meta-analysis of circulatory disease from exposure to low-level ionizing radiation and estimates of potential population mortality risks. Environ Health Perspect. 2012;120(11):1503-11.

17. Adams MJ, Lipsitz SR, Colan SD, Tarbell NJ, Treves ST, Diller L, et al. Cardiovascular status in long-term survivors of Hodgkin's disease treated with chest radiotherapy. J Clin Oncol. 2004;22(15):3139-48.

18. Landy DC, Miller TL, Lipsitz SR, Lopez-Mitnik G, Hinkle AS, Constine LS, et al. Cranial irradiation as an additional risk factor for anthracycline cardiotoxicity in childhood cancer survivors: an analysis from the cardiac risk factors in childhood cancer survivors study. Pediatr Cardiol. 2013;34(4):826-34.

19. Lipshultz SE, Landy DC, Lopez-Mitnik G, Lipsitz SR, Hinkle AS, Constine LS, et al. Cardiovascular status of childhood cancer survivors exposed and unexposed to cardiotoxic therapy. J Clin Oncol. 2012;30(10):1050-7.

20. Lipshultz SE, Lipsitz SR, Sallan SE, Dalton VM, Mone SM, Gelber RD, et al. Chronic progressive cardiac dysfunction years after doxorubicin therapy for childhood acute lymphoblastic leukemia. J Clin Oncol. 2005;23(12):2629-36.

21. Swain SM, Whaley FS, Ewer MS. Congestive heart failure in patients treated with doxorubicin: a retrospective analysis of three trials. Cancer. 2003;97(11):2869-79.

22. Lipshultz SE, Lipsitz SR, Mone SM, Goorin AM, Sallan SE, Sanders SP, et al. Female sex and drug dose as risk factors for late cardiotoxic effects of doxorubicin therapy for childhood cancer. N Engl J Med. 1995;332(26):1738-43.

23. Lipshultz SE, Scully RE, Lipsitz SR, Sallan SE, Silverman LB, Miller TL, et al. Assessment of dexrazoxane as a cardioprotectant in doxorubicin-treated children with high-risk acute lymphoblastic leukaemia: longterm follow-up of a prospective, randomised, multicentre trial. Lancet Oncol. 2010:11(10):950-61.

24. Lipshultz SE, Rifai N, Dalton VM, Levy DE, Silverman LB, Lipsitz SR, et al. The effect of dexrazoxane on myocardial injury in doxorubicin-treated children with acute lymphoblastic leukemia. N Engl J Med. 2004;351(2):145-53.

25. Lipshultz SE, Lipsitz SR, Kutok JL, Miller TL, Colan SD, Neuberg DS, et al. Impact of hemochromatosis gene mutations on cardiac status in doxorubicin-treated survivors of childhood high-risk leukemia. Cancer. 2013;119(19):3555-62.

26. Krischer JP, Epstein S, Cuthbertson DD, Goorin AM, Epstein ML, Lipshultz SE. Clinical cardiotoxicity following anthracycline treatment for childhood cancer: the Pediatric Oncology Group experience. J Clin Oncol. 1997;15(4):1544-52.

27. Velásquez CA, González M, Berrouet MC, Jaramillo N. Cardiotoxicidad inducida por la quimioterapia desde las bases moleculares hasta la perspectiva clínica. Rev Colomb Cardiol. 2016;23(2):104-11.

28. Florescu M, Cinteza M, Vinereanu D. Chemotherapy-induced cardiotoxicity. Mædica. 2013;8(1):59-67.

29. Dolci A, Dominici R, Cardinale D, Sandri MT, Panteghini M. Biochemical markers for prediction of chemotherapy-induced cardiotoxicity: systematic review of the literature and recommendations for use. Am J Clin $\mathrm{Pa}$ thol. 2008;130(5):688-95.

30. Frishman WH, Sung HM, Yee HC, Liu LL, Keefe D, Einzig Al, et al. Cardiovascular toxicity with cancer chemotherapy. Curr Probl Cancer. 1997;21(6):301-60.

31. Pai VB, Nahata MC. Cardiotoxicity of chemotherapeutic agents: incidence, treatment and prevention. Drug Saf. 2000;22(4):263-302.

32. Rang HP. Rang et Dale's pharmacology. Edinburgh: Elsevier, Churchill Livingstone; 2016

33. Hurtado S, Mejía AM, Sanabria A. Cardiotoxicidad por quimioterapia. Un enfoque práctico para el clínico. Insufic Card. 2011;6(3):131-43.

34. Adão R, de Keulenaer G, Leite-Moreira A, Brás-Silva C. Cardiotoxicidade associada à terapêutica oncológica: mecanismos fisiopatológicos e estratégias de prevencão. Rev Port Cardiol. 2013;32(5):395-409.

35. Slørdal L, Spigset O. Heart failure induced by non-cardiac drugs. Drug Saf. 2006;29(7):567-86.

36. Lipshultz SE, Cochran TR, Franco VI, Miller TL. Treatment-related cardiotoxicity in survivors of childhood cancer. Nat Rev Clin Oncol. 2013, 10(12):697-710.

37. Kremer LC, van Dalen EC, Offringa M, Ottenkamp J, Voûte PA. Anthracycline-induced clinical heart failure in a cohort of 607 children: long-term follow-up study. J Clin Oncol. 2001:19(1):191-6.

38. Bagnes C,Panchuk PN, Recondo G. Antineoplastic chemotherapy induced QTc prolongation. Curr Drug Saf. 2010;5(1):93-6. 
39. Serrano C, Cortés J, De Mattos-Arruda L, Bellet M, Gómez P, Saura C et al. Trastuzumab-related cardiotoxicity in the elderly: a role for cardiovascular risk factors. Ann Oncol. 2012;23(4):897-902.

40. Chavez-MacGregor M, Zhang N, Buchholz TA, Zhang Y, Niu J, Elting L et al. Trastuzumab-related cardiotoxicity among older patients with breast cancer. J Clin Oncol. 2013;31(33):4222-8.

41. Lipshultz SE, Sambatakos $P$, Maguire M, Karnik R, Ross SW, et al. Cardiotoxicity and cardioprotection in childhood cancer. Acta Haematol. 2014;132(3-4):391-9.

42. Diamond $M$, Franco V. Preventing and treating anthracycline-related cardiotoxicity in survivors of childhood cancer. Curr Cancer Ther Rev. 2012;8:141-51.

43. Dillenburg RF, Nathan P, Mertens L. Educational paper: decreasing the burden of cardiovascular disease in childhood cancer survivors: an update for the pediatrician. Eur J Pediatr. 2013;172(9):1149-60.

44. Zamorano JL, Lancellotti P, Muñoz DR, Aboyans V, Asteggiano R, et al. Position Paper on cancer treatments and cardiovascular toxicity developed under the auspices of the ESC Committee for Practice Guidelines: The Task Force for cancer treatments and cardiovascular toxicity of the European Society of Cardiology (ESC). European Heart J. 2016;37(36):2768-801.

45. Di Lisi D, Bonura F, Macaione F, Peritore A, Meschisi M, Cuttitta F, et al. Chemotherapy-induced cardiotoxicity: role of the tissue Doppler in the early diagnosis of left ventricular dysfunction. Anticancer Drugs. 2011;22(5):468-72.

46. Nagueh SF, Middleton KJ, Kopelen HA, Zoghbi WA, Quinones MA. Doppler tissue imaging: a noninvasive technique for evaluation of left ventricular relaxation and estimation of filling pressures. J Am Coll Cardiol. 1997;30(6):1527-33

47. Sawaya H, Plana JC, Scherrer-Crosbie M. Newest echocardiographic techniques for the detection of cardiotoxicity and heart failure during chemotherapy. Heart Fail Clin. 2011;7(3):313-21.

48. Sawaya H, Sebag IA, Plana JC, Januzzi JL, Ky B, Cohen V, et al. Early detection and prediction of cardiotoxicity in chemotherapy-treated patients. Am J Cardiol. 2011;107(9):1375-80.

49. Plana JC, Galderisi M, Barac A, Ewer MS, Ky B, Scherrer-Crosbie M, et al. Expert consensus for multimodality imaging evaluation of adult patients during and after cancer therapy: A Report from the American Society of Echocardiography and the European Association of Cardiovascular Imaging. J Am Soc Echocardiogr. 2014;27(9):911-39.

50. Cardinale D, Colombo A, Lamantia G, Colombo N, Civelli M, De Giacomi G, et al. Anthracycline-induced cardiomyopathy: clinical relevance and response to pharmacologic therapy. J Am Coll Cardiol. 2010;55(3):213-20.
51. Alpert JS, Thygesen K, Antman E, Bassand JP. Myocardial infarction redefined a consensus document of The Joint European Society of Cardiology/American College of Cardiology Committee for the redefinition of myocardial infarction. J Am Coll Cardiol. 2000;36(3):959-69.

52. Cardinale D, Sandri MT, Colombo A, Colombo N, Boeri M, Lamantia G, et al. Prognostic value of troponin I in cardiac risk stratification of cancer patients undergoing high-dose chemotherapy. Circulation. 2004;109(22): 2749-54.

53. Nousiainen T, Vanninen E, Jantunen E, Puustinen J, Remes J, Rantala A, et al. Natriuretic peptides during the development of doxorubicin-induced left ventricular diastolic dysfunction. J Intern Med. 2002;251(3):228-34.

54. Cardinale D, Colombo A, Torrisi R, Sandri MT, Civelli M, Salvatici M, et al. Trastuzumab-induced cardiotoxicity: clinical and prognostic implications of troponin I evaluation. J Clin Oncol. 2010;28(25):3910-6.

55. Januzzi JL Jr, Rehman SU, Mohammed AA, Bhardwaj A, Barajas L, Barajas $\mathrm{J}$, et al. Use of amino-terminal pro-B-type natriuretic peptide to guide outpatient therapy of patients with chronic left ventricular systolic dysfunction. J Am Coll Cardiol. 2011;58(18):1881-9.

56. Masson S, Latini R, Anand IS, Barlera S, Angelici L, Vago T, et al. Prognostic value of changes in $\mathrm{N}$-terminal pro-brain natriuretic peptide in Val-HeFT (Valsartan Heart Failure Trial). J Am Coll Cardiol. 2008(12); 52:997-1003.

57. Sandri MT, Salvatici M, Cardinale D, Zorzino L, Passerini R, Lentati $P$ et al. N-terminal pro-B-type natriuretic peptide after high-dose chemotherapy: a marker predictive of cardiac dysfunction? Clin Chem. 2005; 51(8):1405-10.

58. Cil T, Kaplan AM, Altintas A, Akin AM, Alan S, Isikdogan A. Use of $\mathrm{N}$-terminal pro-brain natriuretic peptide to assess left ventricular function after adjuvant doxorubicin therapy in early breast cancer patients: a prospective series. Clin Drug Investig. 2009;29(2):131-7.

59. Fresneau B, Fayech C, Butel T, Haddy N, Valteau-Couanet D, Ou P. Facteurs de risque et surveillance à long terme des complications cardiaques après traitement pour un cancer pendant l'enfance. Rev Med Interne. 2017;38(2):125-32.

60. Shankar SM, Marina N, Hudson MM, Hodgson DC, Adams MJ, Landier W, et al. Monitoring for cardiovascular disease in survivors of childhood cancer: Report from the Cardiovascular Disease Task Force of the Children's Oncology Group. Pediatrics. 2008;121(2):e387-96.

61. Witteles RM, Bosch X. Myocardial protection during cardiotoxic chemotherapy. Circulation. 2015;132(19):1835-45.

62. Nhola LF, Villarraga HR. Rationale for Cardio-Oncology Units. Rev Esp Cardiol. 2017;70(7):583-89. 